\title{
Pengendalian Robot Humanoid menggunakan Metode Speech Recognation Berbasis Android
}

\author{
Hendy Rudiansyah ${ }^{1}$, Gun Gun Maulana ${ }^{2}$, Atep Puja $\mathrm{TH}^{3}$ \\ 1,2,3 Politeknik Manufaktur Bandung \\ Email: hendy_r@polman-bandung.ac.id
}

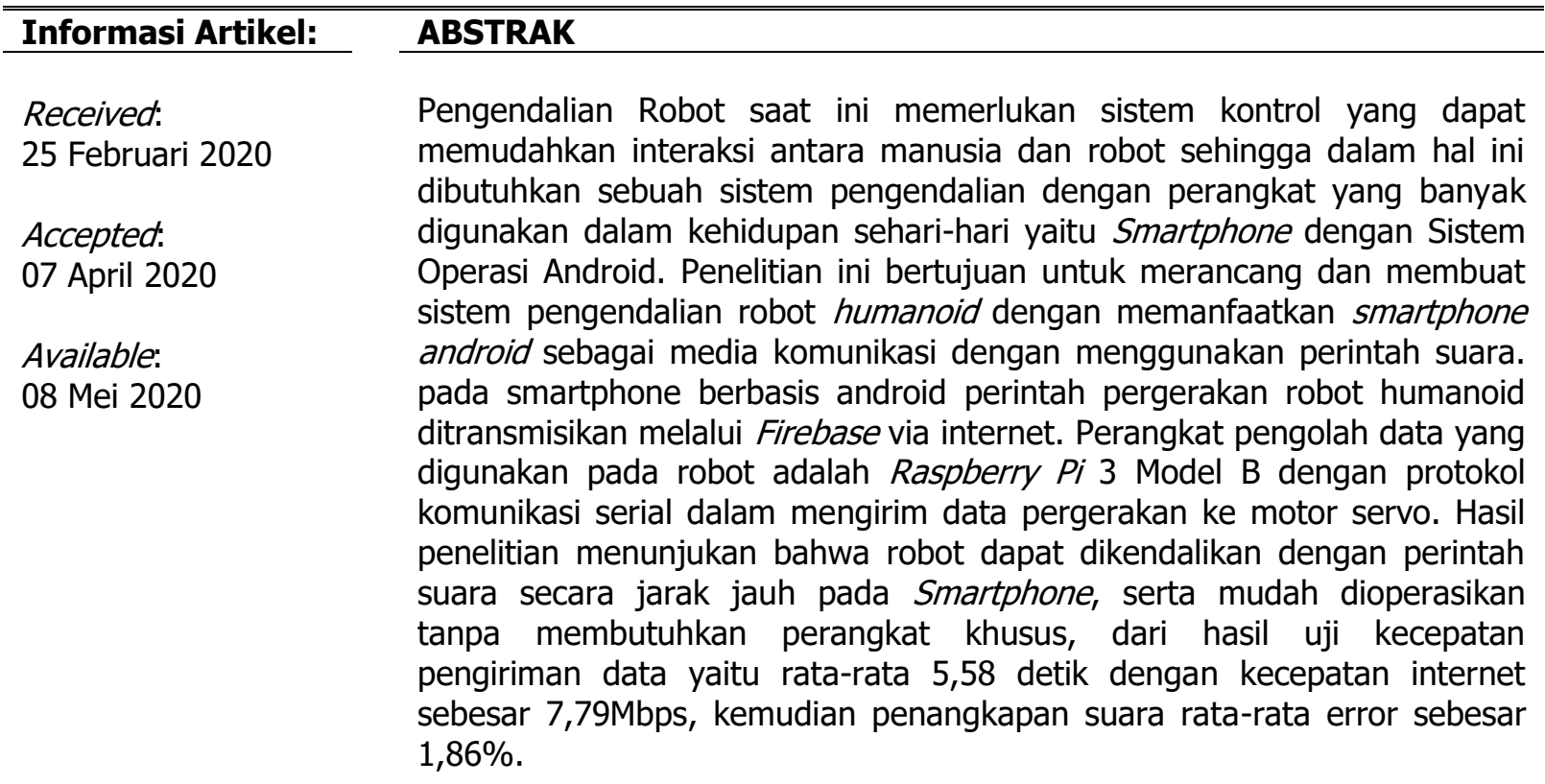

Kata Kunci:

Robot Humanoid Speech recognition Android Raspberry Pi Google Tools

\begin{abstract}
Robot Control currently requires a control system that can facilitate between humans and robots so in this case a control system is needed with a device that is widely used in everyday life, namely a Smartphone with an Android Operating System. This study aims to support and create a humanoid robot control system by using an Android smartphone as a communication and instruction medium using voice commands from users and also internet-based, where the robot can be operated without any distance restrictions. In this study. Robots driven by Voice Input Commands are converted to text using the Google Speech API on Android and as data requests for human driven robots transmitted online through Firebase The data processing device used in the robot is the Raspberry Pi 3 Model $B$ with serial communication in sending movement data to the servo motor. The results showed a robot that can communicate with voice over a long distance Smartphone, and easily help without the need for special devices, from the results of an average data transmission speed of 5.58 seconds with an internet speed of 7.79 Mbps, then moved the average voice error by $1.86 \%$.
\end{abstract}




\section{PENDAHULUAN}

Saat ini perkembangan teknologi sangat maju, diantaranya perkembangan dalam bidang telekomunikasi dan robotika. Pada mulanya orang hanya menggunakan telepon biasa atau telepon rumah dan akhirnya berkembang menggunakan telepon genggam. Seiring perkembangannya. Telepon genggam saat ini juga sudah memiliki sistem operasi seperti komputer, sistem operasi (SO) telepon genggam adalah software utama yang melakukan manajemen dan kontrol terhadap hardware [1].

Bentuknya yang portabel dan mudah dibawa membuat orang menyukainya sebagai alat utama dalam kehidupan sehari-hari. Berbagai macam aplikasi tersedia di smartphone baik yang memiliki antarmuka grafis maupun dengan antarmuka berbasis suara [2]. Antarmuka berbasis suara merupakan terobosan teknologi yang menggantikan peranan input dari keyboard \& mouse. Keuntungan yang didapat dari sistem ini yaitu pada kemudahan dan kecepatan dalam penggunaanya [3]Teknologi berikutnya yang berkembang yaitu teknologi pada bidang robotika [4].

Teknologi robot terus dikembangkan dengan harapan dapat membantu dan mempermudah pekerjaan manusia, hal ini dilakukan untuk pencapaian efisiensi alat yang lebih baik dalam pengoperasiannya di berbagai bidang kehidupan manusia, salah satu pengembangan dibidang robotika yang marak dikembangkan yaitu robot humanoid [5], robot humanoid merupakan salah satu bentuk implementasi teknologi dalam bidang robotika yang memiliki kemampuan menirukan beberapa kegiatan manusia untuk berjalan dan menggerakan beberapa organ tubuh layaknya manusia [6].

Robot humanoid ini banyak fungsinya, karena bentuk robot yang menyerupai manusia sehingga bisa beradaptasi dengan mudah pada lingkungan [7], Robot memiliki dua metode pengendalian yaitu secara manual dan otomatis.Media-media yang digunakan dalam pengendalian robot disebut juga remote control. Pada umumnya pengontrolan robot menggunakan remote control yang menggunakan kabel. Hal ini mempengaruhi ruang gerak robot menjadi terbatas.

Perkembangan ilmu dan teknologi saat ini menuntut kita untuk dapat membuat sistem yang efisiens, mempunyai mobilitas tinggi serta komunikasi antar perangkat yang tidak terbatas oleh jarak. Sehingga dalam hal ini dibutuhkan sebuah sistem pengendalian yang efisien, praktis dan mudah dioperasikan. Dari beberapa penelitian yang telah dilakukan, pengendalian robot humanoid menggunakan perintah suara berbasis internet menggunakan Kinect dan PC/Laptop untuk pengoperasiannya sehingga masih kurang mudah dioperasikan karena memerlukan setting PC dan Kinect [8], selain itu sistem pengendalian mobile robot atau humanoid menggunakan smartphone berbasis bluetooth yang menyebabkan pengguna masih dibatasi jarak dalam komunikasi atau kontrolnya[9][10][11].

Berdasarkan permasalahan tersebut, Pengendalian robot menggunakan perintah suara pada Smartphone dapat memudahkan dalam pengoperasiannya, mudah di akses dimana pengguna tidak perlu mempunyai perangkat khusus untuk mengontrol robot, juga bisa lebih baik dalam hal mobilitasnya jika dibandingkan melalui personal computer yang cenderung statis atau diam [12] dan efisien yaitu solusi mengontrol robot dengan biaya rendah [13]. dan didukung juga sistem berbasis internet dimana penguna dapat mengendalikan robot dari jarak jauh, Perangkat untuk mengontrol menggunakan smartphone dengan sistem operasi android yang memiliki kompabilitas yang baik dengan perangkat lunak Android App Inventor yang mana digunakan sebagai software antarmuka pada tugas ini, sedangkan untuk 
pemilihan microcontroller yaitu menggunakan Raspberry Pi 3 Model B dikarenakan lebih compatible dalam menjalankan sistem yang berbasis internet [14]. Oleh karena itu berdasarkan hal tersebut, maka dengan pembuatan sistem pengendalian robot humanoid menggunakan perintah pengenalan suara pada smartphone berbasis internet ini dapat mengoptimalkan kinerja sistem,pengontrolan yang lebih praktis, mudah dioperasikan serta diharapkan juga dapat bermanfaat bagi pengembangan ilmu robotika untuk pemanfaatan lainnya.

\section{METODE PENELITIAN}

Pada penelitian ini, arsitektur sistem dalam pengendalian robot humanoid tipe BRAT menggunakan perintah suara pada Smartphone OS Android. Untuk lebih jelasnya mengenai Gambaran umum sistem dapat dilihat pada Gambar dibawah ini.

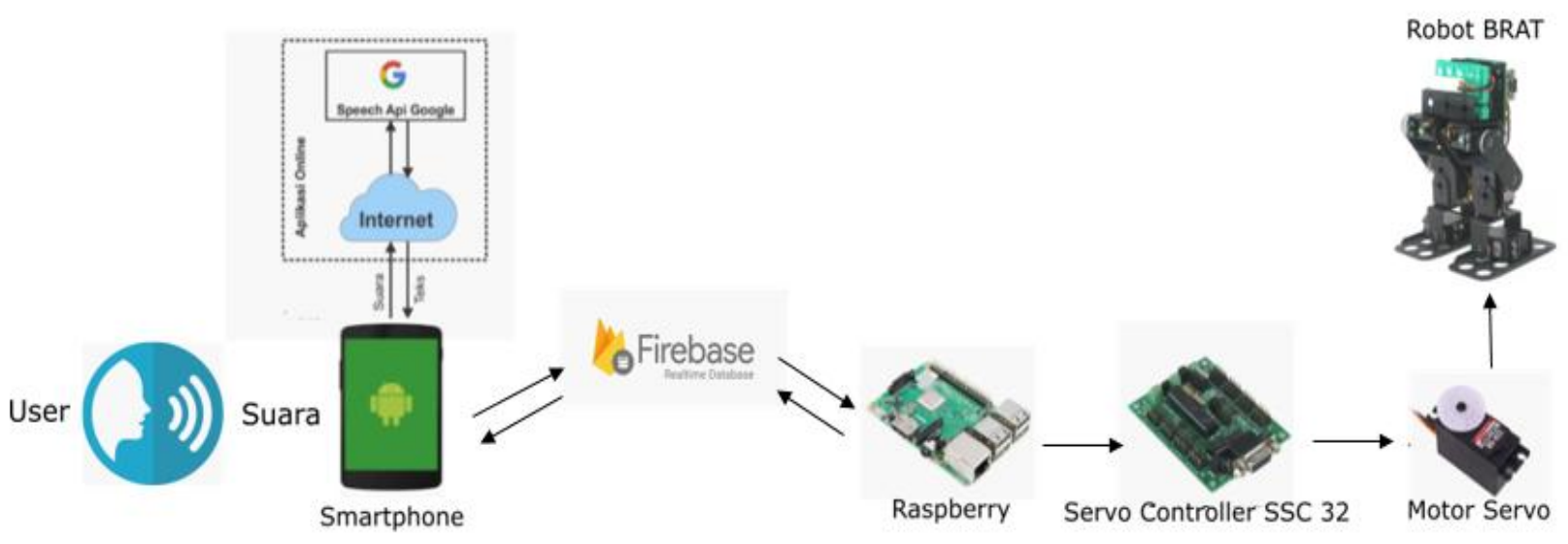

Gambar 1. Gambaran Umum Sistem

Gambar 1 menunjukkan Gambaran Umum Sistem dimana pengguna atau user memberikan input berupa perintah suara yang kemudian ditangkap oleh mikrofon pada Smartphone. Input suara di-record pada perangkat smartphone kemudian dikirimkan ke server Google. Server Google memiliki tugas melakukan pengenalan dan mengubahnya menjadi teks menggunakan Algoritma Hidden Markov Model (HMM).

Hasil konversi suara menjadi teks pada server Google akan dikirimkan kembali ke perangkat Android. Kemudian teks tersebut di ubah menjadi suatu data perintah pada perangkat lunak Android, kemudian data tersebut dikirim dari perangkat lunak Android ke sebuah online database yaitu Firebase. Setelah data tersebut berhasil terkirim pada database maka selanjutnya data perintah yang terdapat pada database tersebut akan diakses atau diterima oleh perangkat Raspberry Pi yang terdapat pada robot untuk diolah lebih lanjut, dimana data perintah yang diterima oleh perangkat Raspberry Pi akan diolah dan dieksekusi menjadi sebuah program pergerakan robot

\subsection{Perancangan Sistem}

Robot dibuat dengan menggunakan berbagai perangkat keras dan perangkat lunak untuk dapat berfungsi sebagaimana mestinya. Arsitektur sistem robot dirancang seperti yang ditunjukan oleh Gambar 1. Terdapat beberapa varian solusi perangkat keras dan perangkat 
lunak yang dapat digunakan, oleh karena itu pada perancangan awal perlu dilakukan analisa solusi mana yang akan digunakan.

\subsubsection{Perancangan Mekanik}

Konstruksi robot bipedal yang digunakan adalah Lynxmotion Bipedal Robotic Articulating Transport. Robot ini memiliki tiga derajat kebebasan yang merepresentasikan sendi pada lutut, tumit dan pinggul di setiap kaki robot.
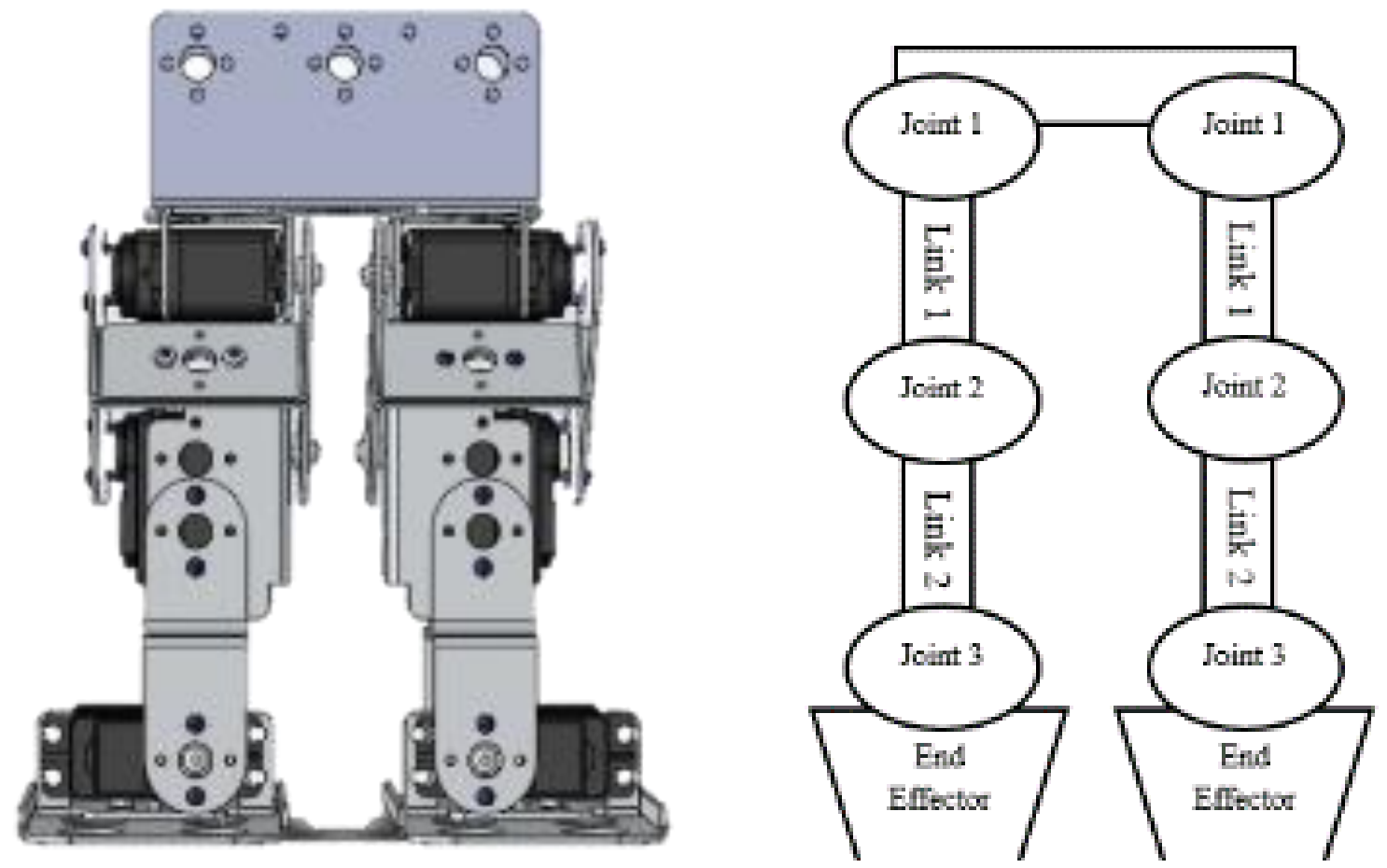

Gambar 2. Konstruksi Robot Bipedal (Kiri) Model Transformasi (Kanan)

Pada Gambar 2 perangkat mekanik yang digunakan pada penelitian ini yaitu berupa komponen pembentuk robot seperti link, joint dan end effector, dimana robot dalam hal ini menjadi objek yang dikendalikan sistem. Sistem mekanik robot yang dibangun terdiri dari motor servo sebagai joint penghasil sudut, dan untuk linknya terdiri alumunium profile karena kokoh dan memiliki ketahanan terhadap karat, selain itu bahan ini ringan sehingga tidak terlalu membebani motor servo.

Selain itu, desain robot pada penelitian ini mengacu pada fungsi utama dari pada robot BRAT yaitu, robot yang difokuskan untuk bekerja menggunakan kedua kakinya dengan sudut kebebasan minimum 3 DoF pada setiap kakinya, yaitu 2 Dof pada bagian pinggang ( $h i p$ ) dan lutut ( $k$ nee) dengan orientasi ke depan yang berfungsi untuk melangkah, dan 1 DoF pada pergelangan kaki (angkle).

\subsubsection{Perancangan Elektrik}

Pada rancangan perangkat elektrik merupakan proses instalasi sistem dimana terdapat hubungan-hubungan yang terjalin dalam suatu domain. Tahapan ini meliputi instalasi perangkat Raspberry Pi 3 Model B, PL2303 USB to TTL dengan perangkat keras mekanik, instalasi Servo Controller SSC-32 pada robot humanoid BRAT beserta wiring pengalamatan tiap-tiap servo. Untuk lebih jelasnya dapat dijelaskan pada Gambar 3 berikut. 


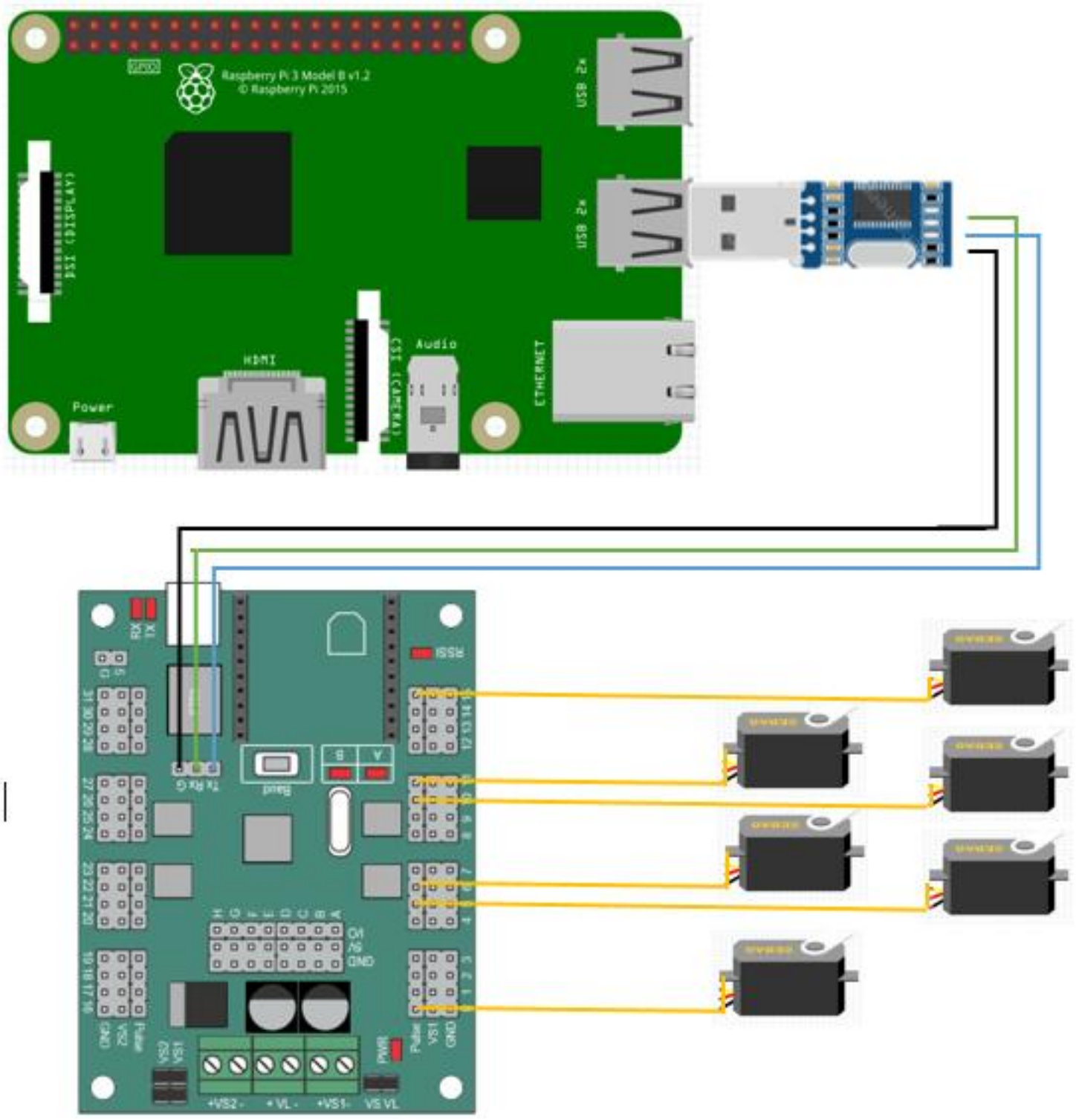

Gambar 3. Skematik Rangkaian Sistem Elektrik Secara Keseluruhan

Pada Gambar 3 dapat dijelaskan bahwa perangkat Raspberry Pi terhubung ke servo controller SSC-32 melalui modul USB TTL PL2303 yang berfungsi untuk melakukan komunikasi serial saat mengirim data pergerakan motor servo.

\subsubsection{Perancangan Program \& Aplikasi Android}

Pada pembuatan program, penulis menentukan terlebih dahulu parameter-parameter yang digunakan. Berikut diagram alir proses pembuatan program: 


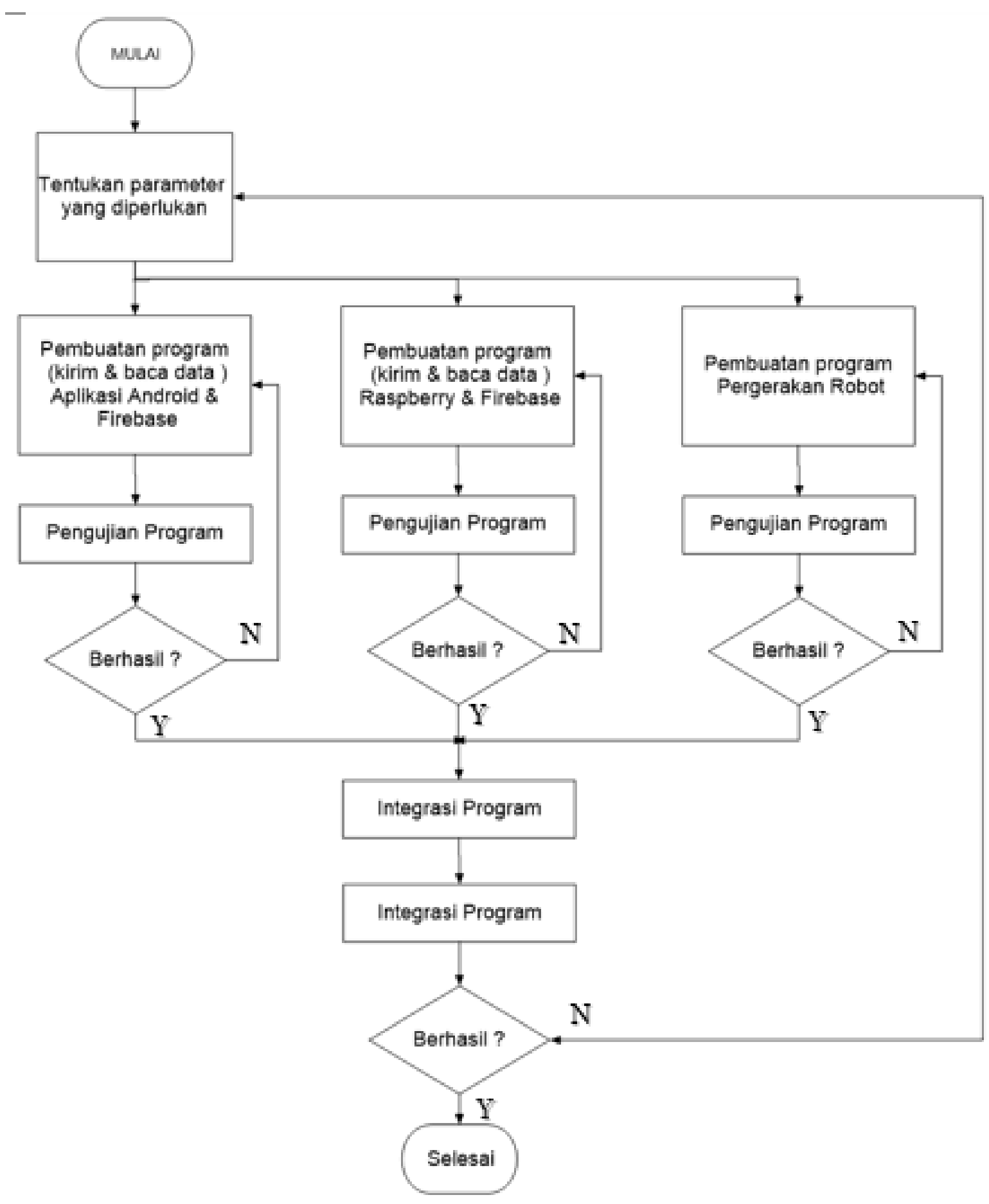

Gambar 4. Tahapan pembuatan program

Pada Gambar 4 adalah program antarmuka aplikasi android ,kemudian program perintah atau komunikasi antara raspberry dan firebase dan program untuk gerakan robot sesuai instruksi Selanjutnya, untuk memberikan perintah-perintah pada robot, dibutuhkan antarmuka yang dapat membantu pengguna agar dengan mudah dapat melakukan kontrol kepada robot yaitu menggunakan Smartphone OS Android dan Aplikasi Android.

Pada penelitian ini untuk membuat program antarmuka menggunakan App Inventor yang merupakan sebuah aplikasi web perangkat lunak Android yang dapat digunakan untuk 
melakukan pengembangan aplikasi Android, App Inventor menggunakan antarmuka grafis, yang memungkinkan pengguna untuk men-drag-and-drop objek visual untuk menciptakan aplikasi yang bisa dijalankan pada perangkat Android. Desain dan target akhir program antarmuka agar pembuatan antarmuka lebih terarah. Berikut adalah desain rancangan interface.

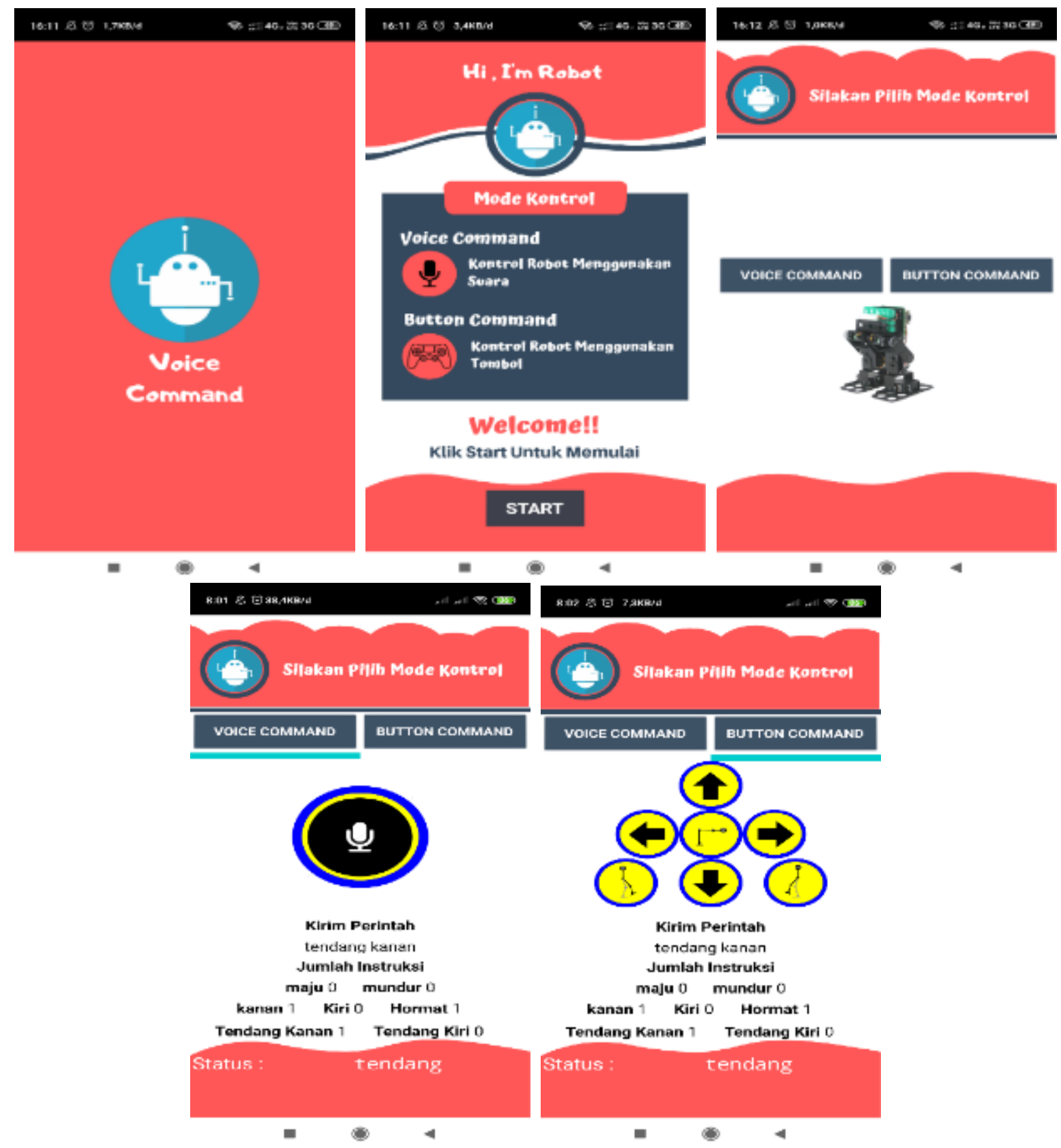

Gambar 5. Tampilan antarmuka

Gambar 5 merupakan tampilan desain akhir pemrograman antarmuka, dimana terdapat beberapa bagian untuk memberikan perintah robot.Pada Screen terdapat tombol start untuk memulai proses pemberian instruksi. Selanjutnya terdapat Screen untuk memilih mode pengontrolan ,ada 2 kontrol menggunakan Voice Command yaitu kontrol robot menggunakan suara dan Button Command untuk mengontrol robot dengan tombol dan juga ada beberapa informasi seperti perintah yang dikirimkan dan status terakhir robot. 


\subsection{Pemodelan}

Pemodelan dilakukan terhadap konstruksi model robot humanoid. Secara fisik, model robot humanoid BRAT memiliki 3 bagian utama pada setiap kakinya, yaitu bagian pergelangan kaki (angk/e), lutut (knee) dan pinggang (hip).

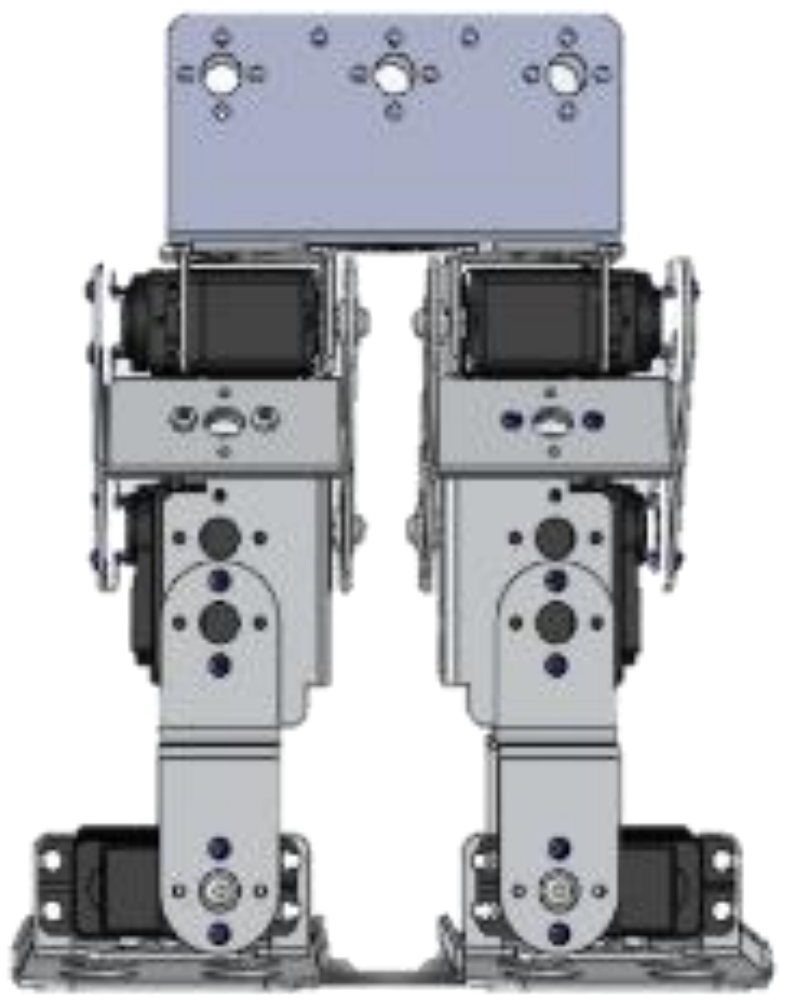

Gambar 6. Bagian Fisik Robot Humanoid BRAT

Dari Gambar 6 bagian fisik robot humanoid dapat dibuat pemodelan berupa stick diagram untuk mempermudah perhitungan dan analisa. Pemodelan robot diperlukan untuk menyelesaikan permasalahan kinematika robot.

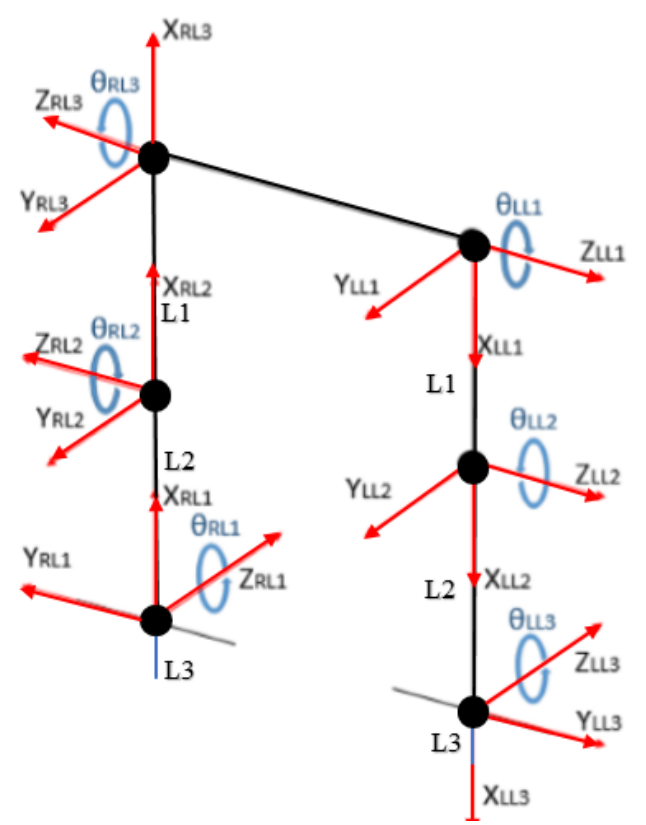

Gambar 7. Pemodelan stick diagram model robot humanoid BRAT 
Gambar 7. Merupakan pemodelan robot humanoid yang dibuat berdasarkan kemampuan gerak robot. Untuk melakukan gerakan berjalan maka kaki robot harus bergerak pada posisi tertentu. Inverse kinematik diterapkan pada robot ini untuk memudahkan menggerakkan kaki untuk mencapai posisi tujuan dengan memberikan masukan posisi yang dituju dan langsung diperoleh nilai dari parameter joint kaki robot. Perhitungan inverse kinematik posisi kaki robot ini dilakukan dengan pendekatan geometri dengan menerapkan rumus segitiga (trigonometri) pada kaki robot. Robot biped yang dirancang dalam penelitian ini mempunyai 3 derajat kebebasan yang bergerak pada 2 sumbu yaitu sumbu $x$ dan sumbu $y$, sehingga langkah yang tepat untuk mengGambarkan geometri pergerakan kaki robot adalah dengan menggunakan koordinat kartesius.

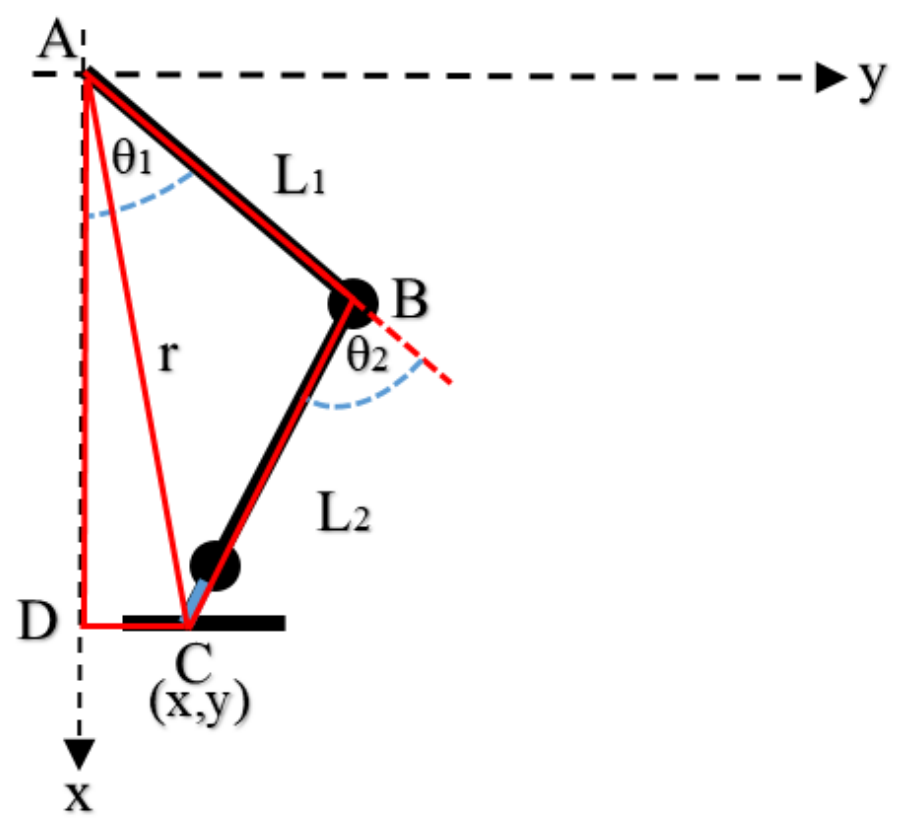

Gambar 8. Model Kaki Pada Koordinat X dan Y

Gambar 8. Adalah cara mendapat nilai sudut $\theta_{1}$ dan $\theta_{2}$, dapat dimanfaatkan bantuan dari dua buah segitiga, yaitu segitiga ACD dan segitiga $A B C$. Jadi sebelum mencari sudut $\theta_{1}$ dan $\theta_{2}$ terlebih dahulu harus mengetahui besar sudut-sudut q1, q2 dan q3 dengan menggunakan persamaan trigonometri
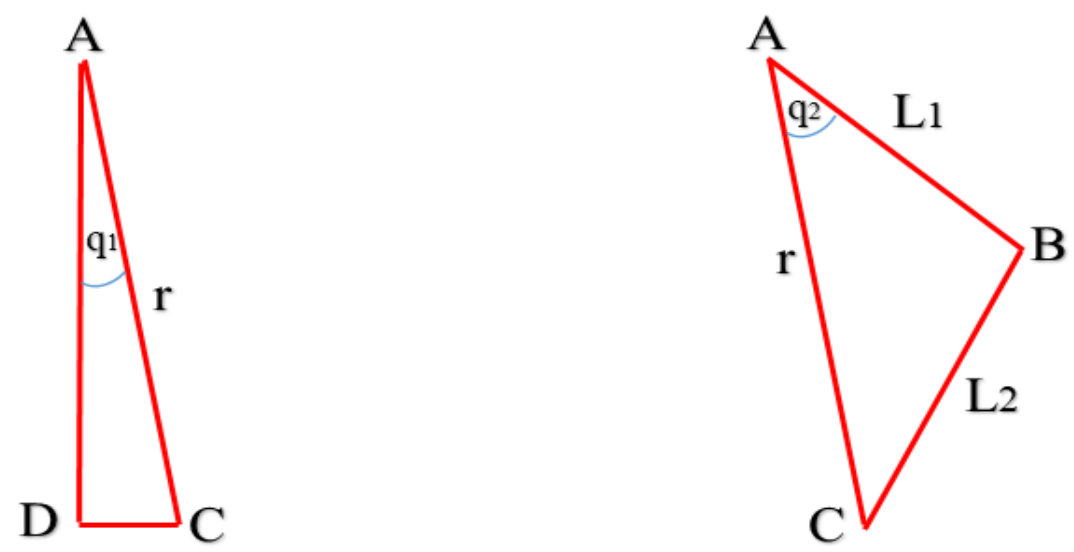

Gambar 9. Segitiga ACD (a) Segitiga ABC (b) 
Dari Gambar 9 (a) segitiga ACD berbentuk segitiga siku-siku, sehingga untuk mencari panjang dari $r$ dapat menggunakan rumus phytagoras. Untuk panjang $\mathrm{x}$ dan panjang $\mathrm{y}$ merupakan nilai dari posisi end effector yang telah diberikan pada saat penginputan. Jadi untuk panjang $r$ dapat dicari dengan rumus pitagoras :

$$
\begin{aligned}
& r=\sqrt{x^{2}+y^{2}} \\
& q_{1}=\arccos \left(\frac{x}{r}\right) \\
& q_{2}=\arccos \frac{L_{1}{ }^{2}+r^{2}-L_{2}{ }^{2}}{2 L_{1}{ }^{2} r} \\
& \theta_{1}=q_{1}+q_{2}
\end{aligned}
$$

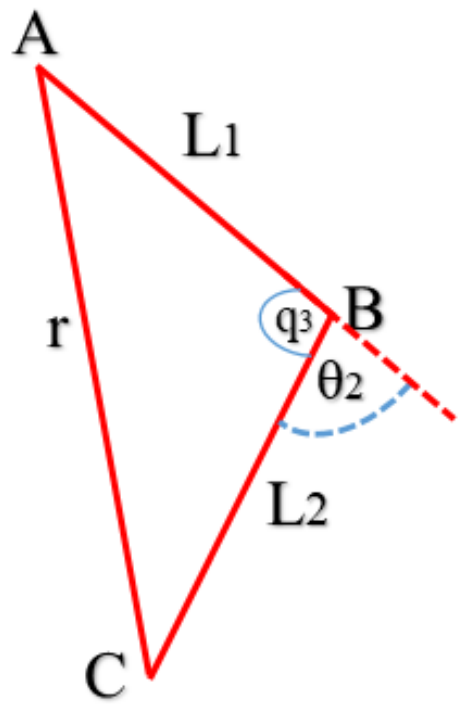

Gambar 10. Segitiga ABC

Gambar 10. Menunjukkan nilai sudut $\theta_{1}$ dan $\theta_{2}$ didapatkan, maka nilai dari kedua sudut tersebut yang nantinya dikirim ke motor servo untuk menggerakan kedua kaki robot biped, kemudian untuk sudut $\theta_{3}$

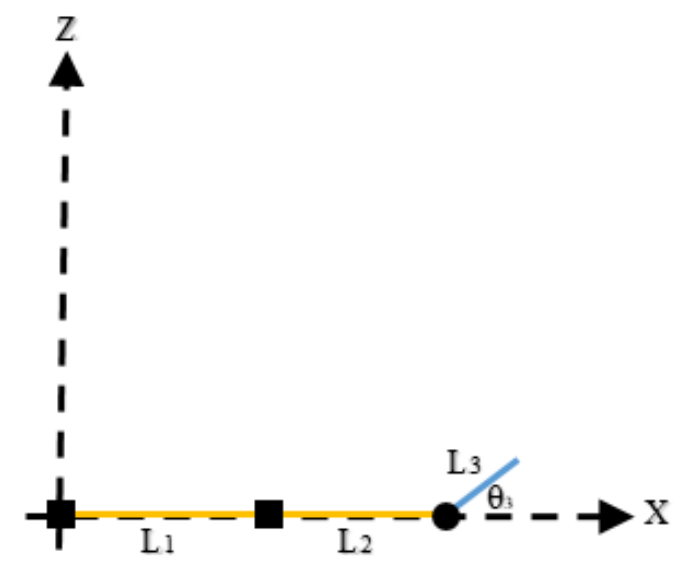

Gambar 11. Sumbu X dan Z

Gambar 11. Bagaimana mendapatkan nilai $\theta 1, \theta 2$ dan $\theta 3$ berdasarkan bentuk geometri robot. Pada aktualnya setiap sudut yang dihasilkan masing-masing joint mempunyai error yang beragam, maka diperlukan suatu metode kalibrasi pada tiap joint. Karena penyebab error dari joint tersebut berasal dari instalasi motor servo pada rangka yang tidak simetris, maka solusi kalibrasinya ialah dengan cara menyesuaikan antara sudut 0 motor (PWM) 
dengan sudut 0 pada sendi, dimana proses tersebut dilakukan ketika merancang program pergerakan robot.

\section{HASIL DAN PEMBAHASAN}

\subsection{Pengujian Koneksi Android dan Raspberry pi}

Untuk memenuhi tuntutan sistem, bagian terpenting dari tuntutan penelitian ini adalah pengaplikasian sistem pengendalian robot menggunakan perintah suara berbasis internet pada Smartphone berbasis Android. Terdapat 7 perintah suara yang bisa diberikan oleh pengguna dalam mengendalikan robot. Dimana gerakan robot yang sudah ditentukan tersebut tersimpan dalam program Python pada perangkat Raspberry $\mathrm{Pi}$ pada robot. Berdasarkan lingkupnya sistem pada penelitian ini terdapat dua lingkup yaitu lingkup komponen pengendali dan lingkup komponen objek, Pertama kita harus pastikan kedua komponen tersebut terkoneksi internet, ketika

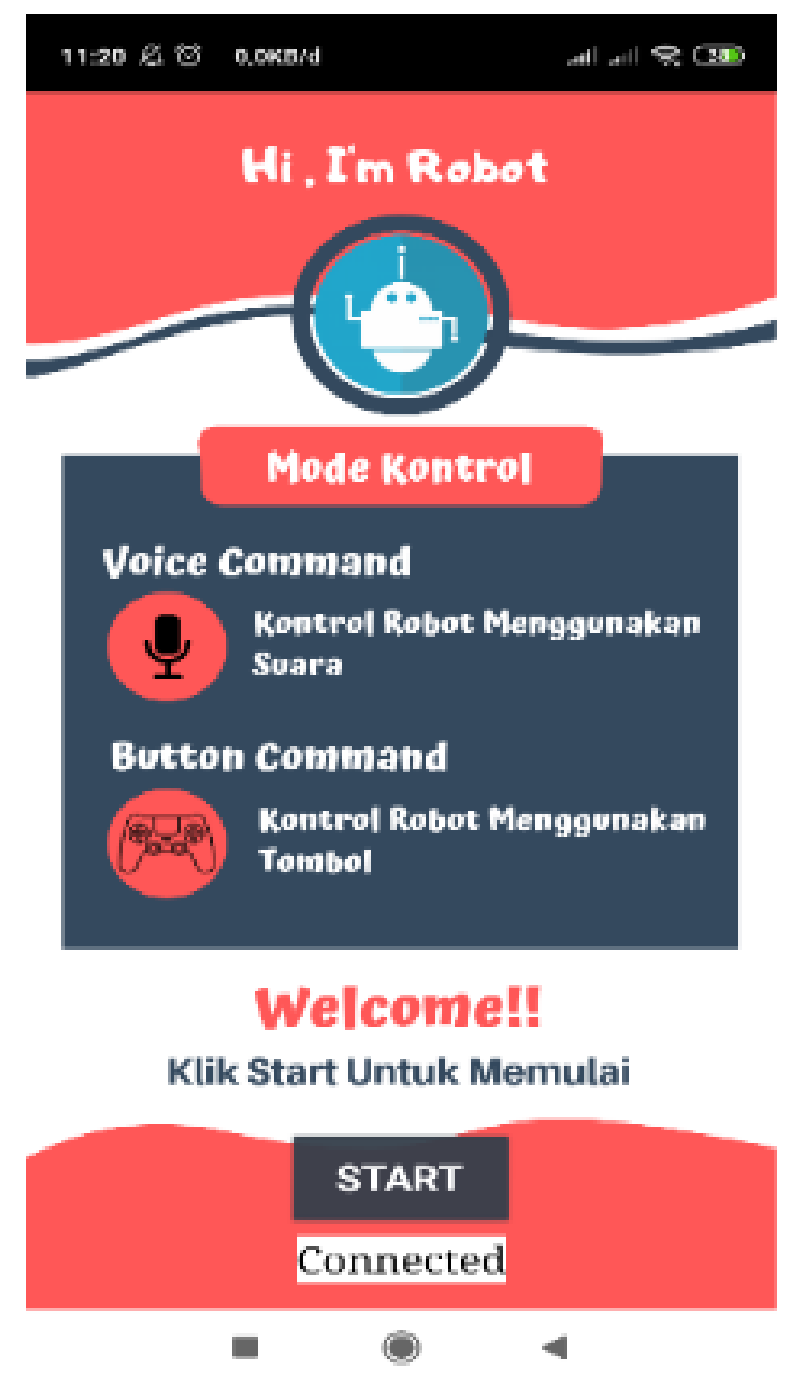

Gambar 12. Raspberry Sudah Tersambung dengan Antarmuka Android

Gambar 12. Menunjukan Raspberry Sudah Tersambung dengan Antarmuka Android dimana pada saat program dari pada dua komponen tersebut dijalankan maka kita akan mendapati status pada antarmuka masing-masing perangkat, pada saat perangkat satu sama lain berstatus 
Connected berarti perangkat sudah sudah tersambung dan siap menerima perintah, maka pada saat itu pula pengguna dapat memberikan input berupa suara untuk mengendalikan robot.

\subsection{Pengujian Jarak Kontrol dan Penangkapan Suara}

Pada pengujian kontrol jarak terbukti bahwa robot dapat dikontrol dari jarak jauh, dengan mengujinya dari jarak $17 \mathrm{~km}$ robot dapat bergerak dan Pengujian penangkapan suara dilakukan untuk mengukur seberapa akurat smartphone dan program pengolahan sinyal suara dalam menangkap perintah suara yang diberikan. Berikut data hasil pengujian penangkapan suara menggunakan Michrophone yang terdapat pada Smartphone dapat dijelaskan pada Tabel 1 berikut

Tabel 1. Pengujian Penangkapan Suara

\begin{tabular}{|c|c|c|c|c|c|}
\hline \multirow{2}{*}{ No } & \multirow{2}{*}{ Intruksi Suara } & \multirow{2}{*}{ Jumlah Percobaan } & \multicolumn{2}{|c|}{ Hasil } & \multirow{2}{*}{ Error (\%) } \\
\hline & & & Sesuai & Tidak Sesuai & \\
\hline 1 & Maju & 100 & 98 & 2 & 2 \\
\hline 2 & Mundur & 100 & 99 & 1 & 1 \\
\hline 3 & Kanan & 100 & 97 & 3 & 3 \\
\hline 4 & Kiri & 100 & 98 & 2 & 2 \\
\hline 5 & Tendang Kanan & 100 & 98 & 2 & 2 \\
\hline 6 & Tendang Kiri & 100 & 97 & 3 & 3 \\
\hline 7 & Hormat & 100 & 100 & 0 & 0 \\
\hline & rata-rata & 100 & 98,14 & 1,86 & 1,86 \\
\hline
\end{tabular}

Berdasarkan data pada Tabel 1 di atas dapat disimpulkan bahwa secara keseluruhan penangkapan suara memiliki akurasi sebesar $98,14 \%$ dalam menangkap perintah suara yang diberikan. Dari hasil pengujian terdapat nilai error sebesar 1,86\% .Dari hasil tersebut terdapat error yang disebabkan oleh beberapa masalah yaitu tidak terbacanya perintah suara, dari masalah tersebut terdapat kemungkinan penyebab diantaranya karena ketidakjelasan suara sehingga tidak ada respon pembacaan atau karena koneksi internet yang tidak stabil. Selain itu masalah lain yang sering muncul ialah salah pembacaan perintah suara, kemungkinan besar masalah ini disebabkan karena ketidakjelasan atau kemiripan suara yang tertangkap sehingga menghasilkan karakter suara yang tertangkap menjadi jauh dari program perintah suara yang dimaksud, malah justru lebih mirip atau mendekati karakter suara dari perintah yang lainnya, sehingga akhirnya program lebih memilih perintah yang lebih mendekati karakter suara yang tertangkap tersebut.

\subsection{Pengujian Pengiriman Data dari Smartphone ke Raspberry}

Pengujian ini untuk mengetahui seberapa cepat waktu pengiriman perintah dari antarmuka ke raspberry atau pergerakan robot, Pada penelitian ini terjadi sebuah aktivitas komunikasi antara Smartphone dengan Raspberry Pi dengan sistem yang terkoneksi internet dalam mengakses data, dimana terdapat dua data, yaitu data perintah dan data pembacaan. 
Pengendalian Robot Humanoid Menggunakan Metode Speech Recognation Berbasis Android

Tabel 2. Pengujian Kecepatan Pengiriman Data

\begin{tabular}{ccc}
\hline No & Waktu (s) & Kecepatan Internet (Mbps) \\
\hline 1 & 4,291 & 8 \\
\hline 2 & 6,208 & 7,44 \\
\hline 3 & 3,9 & 9,43 \\
\hline 4 & 2,088 & 9,86 \\
\hline 5 & 6,851 & 6,02 \\
\hline 6 & 12,01 & 5,23 \\
\hline 7 & 6,844 & 6,04 \\
\hline 8 & 4,044 & 8,15 \\
\hline 9 & 5,989 & 8,49 \\
\hline 10 & 3,653 & 9,3 \\
\hline Rata-rata & 5,5878 & 7,796 \\
\hline
\end{tabular}

\section{Pengujian Kecepatan Kirim Data}

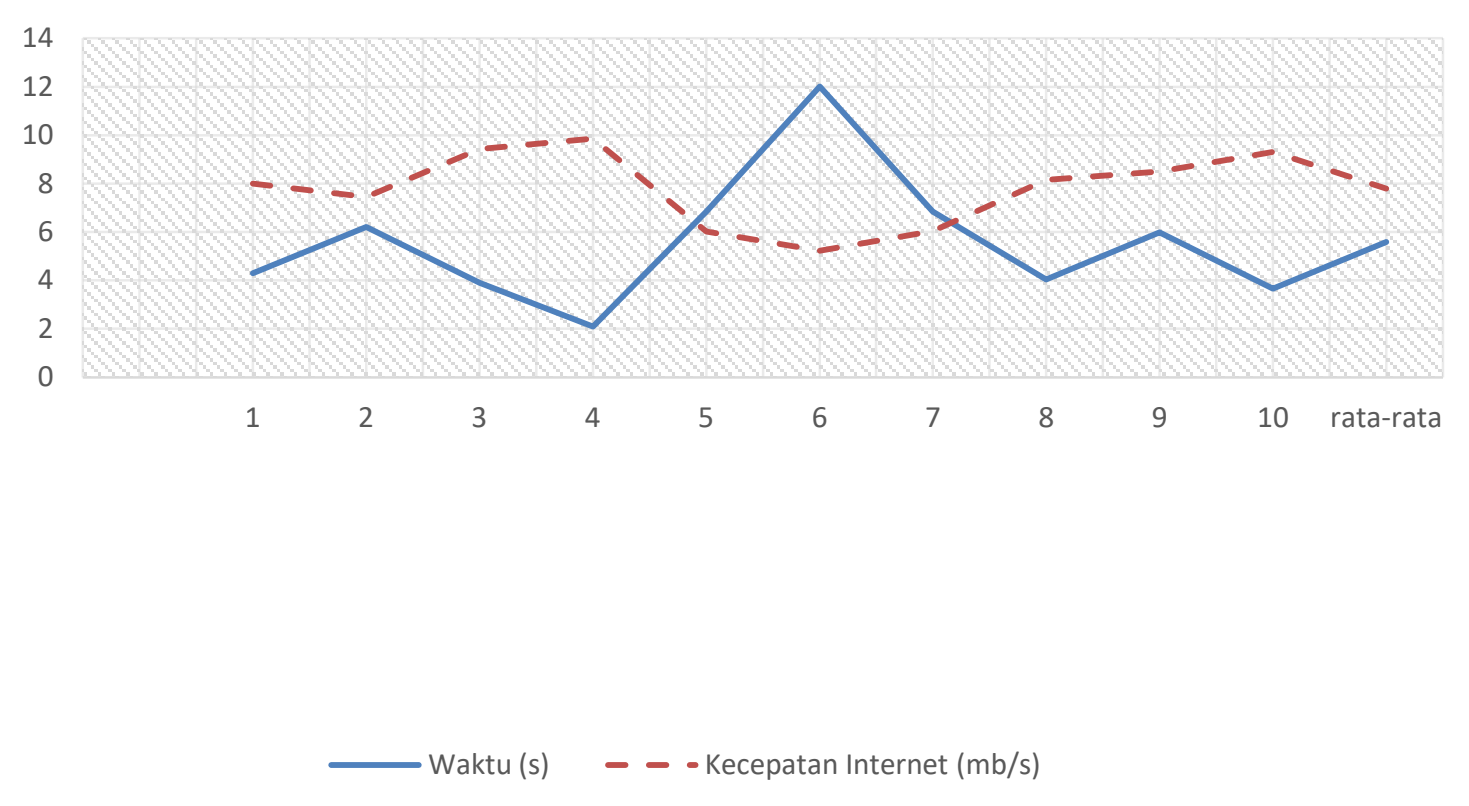

Gambar 13. Pengujian Kecepatan Pengiriman Data

Pada Tabel 2 dan Gambar 13 menunjukan bahwa waktu rata-rata yang diperlukan untuk mengirim dan menerima data dari Smartphone ke Rapsberry pi sehingga menjadi pergerakan robot yaitu 5,58 detik dengan kecepatan rata-rata internet 7,79 Mbps. Semakin cepat internet semakin cepat juga data terkirim. 


\subsection{Pengujian Pergerakan}

\subsubsection{Maju dan Mundur}

Pengujian dilakukan dengan memberikan perintah maju atau mundur ke robot, kemudian setelah robot bergerak, dilakukan pengukuran posisi robot dari posisi awalnya dengan menggunakan jangka sorong.

Tabel 3. Pengujian Gerakan Maju $15^{\circ}$

\begin{tabular}{ccccccc}
\hline \multirow{2}{*}{ NO } & \multicolumn{2}{c}{ Jarak Terhitung $(\mathbf{m m})$} & \multicolumn{2}{c}{ Jarak Terukur $(\mathbf{m m})$} & \multicolumn{2}{c}{ Error $(\%)$} \\
\cline { 2 - 7 } & Kanan & Kiri & Kanan & Kiri & Kanan & Kiri \\
\hline 1 & 32,6 & 32,6 & 35,2 & 33,3 & 7,98 & 2,15 \\
\hline 2 & 32,6 & 32,6 & 35 & 34,3 & 7,36 & 5,21 \\
\hline 3 & 32,6 & 32,6 & 35 & 34,2 & 7,36 & 4,91 \\
\hline 4 & 32,6 & 32,6 & 34,2 & 34,45 & 4,91 & 5,67 \\
\hline 5 & 32,6 & 32,6 & 34,05 & 34,45 & 4,45 & 5,67 \\
\hline 6 & 32,6 & 32,6 & 33,45 & 33,25 & 2,61 & 1,99 \\
\hline 7 & 32,6 & 32,6 & 34,3 & 34,25 & 5,21 & 5,06 \\
\hline 8 & 32,6 & 32,6 & 34,25 & 34,05 & 5,06 & 4,45 \\
\hline 9 & 32,6 & 32,6 & 34,35 & 33,3 & 5,37 & 2,15 \\
\hline 10 & 32,6 & 32,6 & 34,2 & 34,35 & 4,91 & 5,37 \\
\hline Rata-rata & 32,6 & 32,6 & 34,4 & 33,99 & 5,52 & 4,26 \\
\hline
\end{tabular}

Pada Tabel 3. Terliat langkah maju dan mundur pergerakan robot dirancang 1 langkah. Dimana setiap langkah, masing-masing kaki bekerja dengan sudut $15^{\circ}$, dengan perhitungan forward kinematik didapatkan nilai 16,3 mm untuk perpindahan 1 kaki. Untuk bergerak maju robot melakukan 2 kali perpindahan yaitu perpindahan kaki kanan dan kaki kiri, sehingga disimpulkan bahwa untuk bergerak maju robot akan bergerak sejauh $32,6 \mathrm{~mm}$.

\section{KESIMPULAN}

Berdasarkan pengujian yang dilakukan terhadap sistem yang dibangun dan selama proses penyusunan karya tulis ini, dapat ditarik beberapa kesimpulan sebagai berikut:

1. Penggunaan Perintah Suara pada Smartphone dapat diaplikasikan untuk memberikan instruksi yang mudah dan praktis. Pengguna dapat memilih instruksi yang akan diberikan pada robot melalui antarmuka Aplikasi Android

2. Robot bipedal dapat melakukan pergerakan sesuai dengan pilihan pengguna

3. Perintah suara dapat ditangkap menggunakan dengan rata-rata error sebesar $1,86 \%$.

4. Kecepatan Pengiriman Data Perintah sampai menjadi gerakan robot mempunyai rata-rata waktu 4,58 detik dengan kecepatan rata-rata internet pada masing masing perangkat yaitu sebesar 7,79 Mbps dimana antara perangkat satu sama lain mempunyai koneksi pada operator jaringan seluler yang sama pada saat pengujian.

5. Robot mampu melakukan pergerakan sesuai dengan perintah suara yang diberikan, dimana pergerakan untuk perintah maju mempunyai error sebesar 4,26\% untuk end effector kaki kiri, dan 5,52\% untuk effector kaki kanan, sedangkan pada perintah mundur empunyai error sebesar 2,3\% untuk end effector kaki kiri, dan 3,01\% untuk effector kaki kanan.

\section{REFERENSI}

[1]. M. Agung, P. Negara, and S. Laksono, "Jurnal Rekayasa Elektrika," vol. 13, no. 36, 2017.

[2]. Supriyanta, P. Widodo, and B. M. Susanto, "Aplikasi Konversi Suara Ke Teks Berbasis 
Pengendalian Robot Humanoid Menggunakan Metode Speech Recognation Berbasis Android

Android Menggunakan Google Speech Api," Bianglala Inform., vol. 2, no. 2, pp. 11-19, 2014.

[3]. T. Bjerrum and W.- Gladrow, "Smart Home Dengan Speech Recognation Melalui Bluetooth Berbasis Android," pp. 1-14, 2017.

[4]. S. Soim and B. Joni, "Perancangan Robot Humanoid Berbasis Mikrokontroler," no. November, pp. 1-6, 2015.

[5]. E. Sulistyo, "Sistem Komunikasi Robot Humanoid Dalam Aplikasi Robot Penari," Semin. Nas. Sains dan Teknol. 2015 Fak. Tek. Univ. Muhammadiyah Jakarta, no. November, pp. 1-5, 2015.

[6]. P. Merupakan, M. Tindakan, T. Tidak, and T. Terpuji, "Penelitian perancangan humanoid robot berbasis atmega128," 2014.

[7]. R. J. Fariz, "Kendali Keseimbangan Pada Robot Humanoid Balance Control on Humanoid Robot," e-Proceeding Eng., vol. 3, no. 2, pp. 1421-1428, 2016.

[8]. G. Maulana, S. Pd, S. B. Bhaskoro, and S. St, "Pengendalian Robot Humanoid B . R . A . $T$. ( Bipedal Robotic Articulating Transport ) Menggunakan Speech Recognition Berbasis InterneT," pp. 1-14.

[9]. J. Nádvorník and P. Smutný, "Remote control robot using Android mobile device," Proc. 2014 15th Int. Carpathian Control Conf. ICCC 2014, no. May 2014, pp. 373-378, 2014.

[10]. H. Rashid, I. U. Ahmed, S. Bin Osman, Q. Newaz, and S. M. T. Reza, "Design and Implementation of a Voice Controlled Robot with Human Interaction Ability," Int. Conf. Comput. Commun. Chem. Mater. Electron. Eng., no. February, pp. 26-27, 2017.

[11]. M. Y. Baihaqi and J. W. Simatupang, "Aplikasi Metode Kontrol Bluetooth Pada Robot Humanoid Berbasis Arduino Mega 2560," vol. 88, pp. 49-56, 2016.

[12]. A. B. Insani and A. S. Handayani, "Implementasi Smartphone Android Dalam Sistem Monitoring Posisi Pada Mobile Robot," pp. 1-5, 2017

[13]. M. K. Pathak, J. Khan, A. Koul, R. Kalane, and R. Varshney, "Robot Control Design Using Android Smartphone," pp. 31-33, 2015.

[14]. F. T. Industri, sistem pengaturan keseimbangan robot humanoid untuk berdiri dan berjalan pada for standing and walking on the inclined. 2016.T. Aldi, "Monitoring Suhu Ruangan Server. 
Hendy Rudiansyah , Gun Gun Maulana , Atep Puja 